\title{
Research on Gas Drainage Pump Design and Prevention Measures in Gas-rich Mine
}

\author{
Yang Shouguo $^{1,2}$, Lu Xuefu ${ }^{1,2}$, Jin Jia ${ }^{1,2}$ \\ ${ }^{1}$ College of Safety Science and Engineering, Xi'an University of Science and Technology, Xi'an, China \\ ${ }^{2}$ Key Laboratory of Western Mine Exploration and Hazard Prevention, The Chinese Ministry of Education, Xi' an, China
}

Email address:

Yangsg@xust.edu.cn (Yang Shouguo),260639948@qq.com(Lu Xuefu),461696959@qq.com (Jin Jia)

\section{To cite this article:}

Yang Shouguo, Lu Xuefu, Jin Jia. Research on Gas Drainage Pump Design and Prevention Measures in Gas-rich Mine. International Journal of Energy and Power Engineering. Vol. 8, No. 6, 2019, pp. 88-93. doi: 10.11648/j.ijepe.20190806.13

Received: November 14, 2019; Accepted: December 6, 2019; Published: December 9, 2019

\begin{abstract}
In gas-rich mines, gas problems exist in the process of mining, which not only increases the difficulty of mining coal resources, but also reduces the production of coal mines safety. Typically, gas explosion was one of the most serious disasters in coal mines, which caused large numbers of casualties and destruction of facilities. In order to prevent the gas accident during the mining process in the coal seam of Tashan Mine (which located in Datong, Shanxi Province, China), the No.3 5 coal seam were taken as an example, the gas drainage pumps and the pipe laying methods were designed, basing on its hydrogeological conditions, development methods and coal mining methods. The gas drainage pump with a flow rate of $309.95 \mathrm{~m} 3 / \mathrm{min}$ was designed, which helps to make better use of existing mine gas resources better and more efficiently. In addition, integrated control technologies such as gas drainage, gas concentration monitoring, effective ventilation and control of fire sources were used to reduce the probability of gas explosion in the No.3 5 coal seam of Tashan Mine. Strengthen the prevention and control of gas disasters, so as to ensure the smooth progress of coal mine safety production. The gas drainage system has built with this design, which runs for several months, and achieved a good performance. Therefore, the design approach can be referred to other similar mines.
\end{abstract}

Keywords: Safety Science and Engineering, Gas Explosion, Gas Drainage, Drainage Pump, Prevention Measures

\section{Introduction}

In all coal mine accidents in China, the most serious one is gas explosion. In the process of its occurrence, it is always accompanied by the generation of high temperature and high pressure, which accelerates the flow of surrounding gas, destroys the roadway and equipment, and even endangers people's life and safety. Simultaneously, the coal dust rising during the explosion can easily causes a second round of explosion, increasing the extent of the damage. Therefore, research on gas drainage pump and prevention measures is of great significance for ensuring the safe production of coal mines, the health of workers, the company's property and production efficiency.

In the aspect of gas control, a large number of scholars have performed numerous studies. Wang Cheng et al. [1] investigated the propagation mechanism of large gas explosions; Nian Qifeng et al. [2] based on GRA-ANP-FCE model, have studied and applied the safety assessment methods for coal mine gas explosion accidents; Lalatendu Muduli et al. [3] discussed the application of wireless sensor networks in environmental monitoring of underground coal mines; Song Xiaoyan et al. [4] expounded the application of man-machine-environment system engineering in coal mine safety management; Yang Chunli et al. [5] carried out statistical analysis of gas explosions in coal mine and proposed corresponding measures; Xu Xin [6] put forward the prediction and early warning model of gas explosion disaster under the internet environment of coal mine; Gao $\mathrm{Mu}$ [7] research on coal mine gas monitoring system based on wireless sensor network; Xie Guomin et al. [8] raised the identification method of gas explosion risk model in coal mine based on FOA-SVM model; Chu Tingxiang et al. [9] dished the theory of gas extraction in goaf of "U+I" type coal mining face; Zhang Yiqing [10] conducted the analysis of coal mine gas extraction equipment; Li Guoxiong et al. [11] designed gas drainage piping system and the selection of equipment. In 
the gas explosion-proof measures of the Tashan Mine, the comprehensive gas prevention and control technology in the process of gas drainage and coal mining can be used to suppress gas explosion.

\section{General Situation of Tashan Coal Mine}

\subsection{Hydrogeological Conditions}

Tashan Mine is located in the edge of the Middle East of Datong coal field. The stratum structure is single layer, the dip angle of stratum is less than $5^{\circ}$, the trend is $10^{\circ} \sim$ $50^{\circ}$ in the northeast. The occurrence of most of the strata in the coal field is relatively gentle, some of them have gentle undulation and secondary fold, but it has little influence on coal mining. There are many faults in the mine field, there are 37 faults in the Tashan area, and there are 14 faults with a broken distance of more than $10 \mathrm{~m}$, which will greatly affect the mining of coal seam. There is no collapse column in the field, so there is no effect of collapse column on coal mining. The thickness of sedimentary rock in the well field is up to several hundred meters, and the rock is closely connected with each other, with few fissures. In addition, the precipitation in this area is less, the impermanent annual surface runoff and large surface water body, and the water content of each layer is not strong.

\subsection{Development Method and Coal Seam Mining Method}

Tashan Coal Mine adopts the development method of adit and shaft, the first panel area is mined by the way of roadway strip, and the working face is pushed from north to south. The roadway of the second panel is arranged along the southeast boundary of the mine field, and the working face is arranged along the incline direction. The third panel extends to the northwest at the corner of the main lane until the northern boundary.

The coal mining method of fully mechanized top caving is adopted for the No.3 5 coal seam in the first panel, with a mining height of $3.5 \mathrm{~m}$ and a working face length of $2500 \sim 3500 \mathrm{~m}$. A fully mechanized working face of medium thick coal seam is arranged for the No.4 coal seam. The coal mining method of fully mechanized top caving is also adopted for the No.3 5 coal seam in the second panel.

\section{Design of Gas Drainage System for Tashan Coal Mine}

\subsection{Gas Emission Content of Coal Seam}

The gas content of coal seam increases with the increase of coal metamorphism, and the gas in every coal seam of Tashan Coal Mine is in the gas weathering zone. The gas emission content of each coal seam is shown in Table 1.

Table 1. Gas emission content of coal seam mining in Tashan Mine.

\begin{tabular}{llll}
\hline Coal seam & Gas content $\mathbf{~ m}^{\mathbf{3}} / \mathbf{t}$ & Average gas content $\mathbf{~}^{\mathbf{3}} / \mathbf{t}$ & Permeability coefficient of coal seam $\mathbf{~ m}^{\mathbf{2}} / \mathbf{M P a} \cdot \mathbf{d}$ \\
\hline $8^{\#}$ & $1.125 \sim 2.087$ & 1.606 & 3.132 \\
$2^{\#}$ & $1.534 \sim 2.214$ & 1.829 & 2.325 \\
$4^{\#}$ & $1.117 \sim 2.773$ & 1.945 & 2.090 \\
$3^{\#} \sim 5^{\#}$ & $2.548 \sim 3.482$ & 3.065 & 3.260 \\
\hline
\end{tabular}

With the development of the working face, the absolute gas emission of the mine is increasing year by year. In 2012, the relative and absolute gas emission of the mine were 3.8 $\mathrm{m}^{3} / \mathrm{t}$ and $119.47 \mathrm{~m}^{3} / \mathrm{min}$ respectively. Since 2012 , the mine has been identified as a gas-rich mine. During the normal mining period, the absolute gas emission of the mine is kept at 25 40 $\mathrm{m}^{3} / \mathrm{min}$. When the abnormal gas emission occurs, the absolute gas emission of the working face can reach or even exceed $40 \sim 50 \mathrm{~m}^{3} / \mathrm{min}$. The amount of gas emission from heading face is relatively low. Under normal conditions, the absolute emission of gas is generally stable at $2 \mathrm{~m}^{3} / \mathrm{min}$. According to the measurement index of the feasibility of gas drainage in the mining seam, the permeability coefficient of the No.3 5 coal seam in Tashan Mine is $3.260 \mathrm{~m}^{2} / \mathrm{MPa}^{2} \cdot \mathrm{d}$, and the attenuation coefficient of gas flow in the borehole is $0.572 \sim 0.643 / \mathrm{d}$, so the No.3 5 coal seam in Tashan Mine belongs to the extractable coal seam. According to the calculation method of mine gas emission, when the annual output of Tashan Coal Mine reaches 1.50 million tons per year, the absolute gas emission of the No.3 5 coal seam fully mechanized caving face can reach $46.34 \mathrm{~m}^{3} / \mathrm{min}\left(>5 \mathrm{~m}^{3} / \mathrm{min}\right)$, and the absolute gas emission of the mine can reach 119.47 $\mathrm{m}^{3} / \mathrm{min}\left(>40 \mathrm{~m}^{3} / \mathrm{min}\right)$, and the mine meets the necessary conditions for the gas drainage system.

\subsection{Brief Introduction of Gas Drainage Method}

According to the requirements of gas control in the working face of Tashan Mine, the roof high drainage roadway must run through the whole working face, and the excavation should be in place before the working face is put into production. This can ensure that the roof high drainage roadway can be activated and pumped in time after the working face is started. To lay the foundation for gas control in the initial stage of mining. According to the selection principle of gas drainage and the actual situation of Tashan Mine, the design of the high drainage roadway of the fully mechanized caving face is used to lay down the inclined layered borehole to extract the gas in the coal seam, and the roof high drainage roadway of the fully mechanized caving face is arranged to carry out the goaf. Closed buried pipe is pumped. Parallel with the roof of the No.3 5 coal seam floor of Tashan Mine, the vertical distance between the top and the working face returning road is $20 \mathrm{~m}$, the horizontal offset is 30 $\mathrm{m}$, and in the crack zone above the goaf. The shape of the roadway section can be well maintained, and the gas released from the blasting coal body in the goaf and its surrounding 
area can be easily entered into the roof high drainage roadway, and the tailing of the high pumping lane to the working face can be ensured. The ability to control the concentration of gas in the corner.

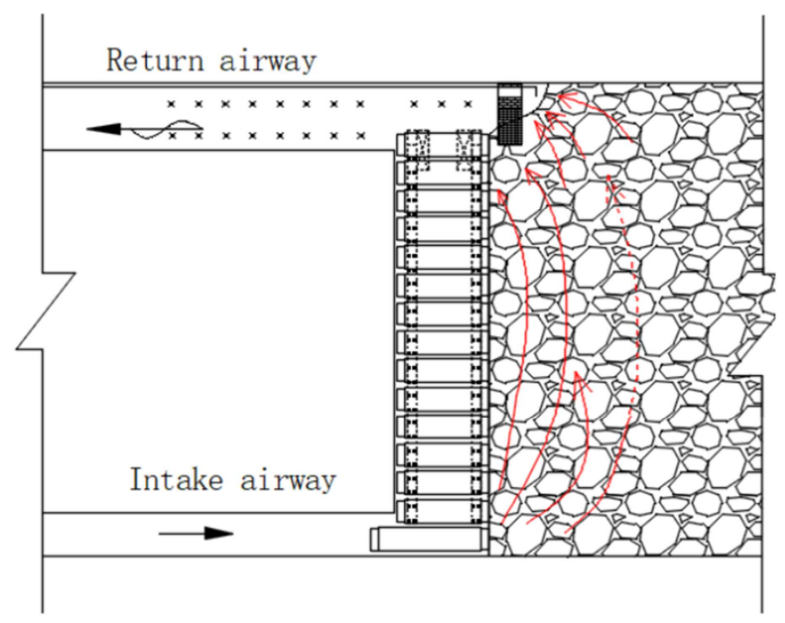

Figure 1. "U" type ventilation gob area in fully mechanized caving face.

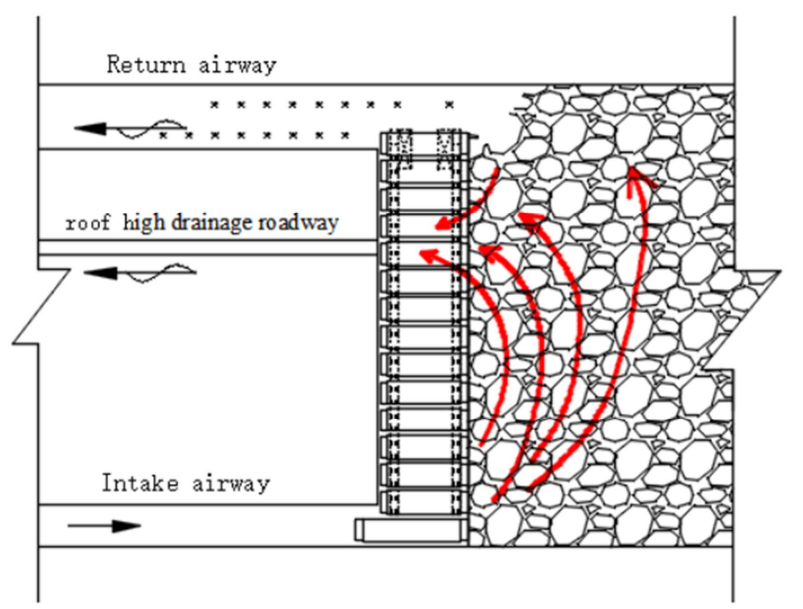

Figure 2. Flow field distribution of " $U+I$ " type ventilation goaf in fully mechanized caving face.

The ventilation mode of the working face changes from "U" to "U+I" shape after the high suction roadway and the working face are connected, and the flow field of the air leakage in the goaf changes with this change. The width of the "three zones" in the goaf is narrowed, and under the effect of ventilation and negative pressure, the gas in the original goaf is taken along the wind flow in the roof high drainage roadway, and the gas that flows out of the goaf is intercepted. Which reduces the gas concentration of the upper corner.

\subsection{Selection of No.3 5 Coal Seam Gas Drainage Pump}

According to the layout of the roadway in Tashan Mine, the pumping station is built in a centralized location for gas drainage in the fully mechanized caving face and low negative pressure pumping in the adjacent layer of gas. The drainage route is: roof high drainage roadway $\rightarrow$ return airway $\rightarrow$ gas pumping station $\rightarrow$ ground, as shown in Figure 3.

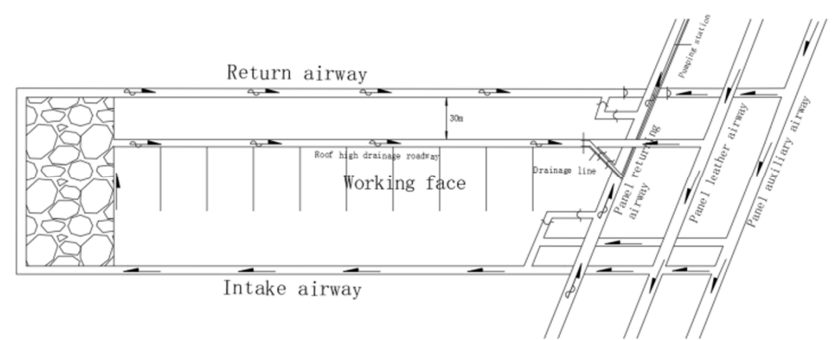

Figure 3. Schematic diagram of the drainage system of the high drainage roadway of the working face roof.

The location of the gas drainage pipeline is: roof high drainage roadway, return airway and ground drilling. Gas drainage pipe diameter is calculated with maximum throughput and safe flow rate $(5 \sim 12 \mathrm{~m} / \mathrm{s})$ and matched to the pumping equipment. The reserve amount of the pumping system pipe is $10 \%$. The total resistance of the mine drainage system must be calculated according to the maximum resistance of the pipe network, and the total resistance of the drainage pipeline is composed of frictional resistance and local resistance. The local resistance of the pipeline generally takes $10 \% \sim 20 \%$ of the frictional resistance. In view of the actual pumping capacity of the pump, the convenience of pipeline transportation and installation work, the pumping design adopts formula (1) to calculate the gas drainage pipe diameter [12]:

$$
D=0.1457(Q / V)^{0.5}
$$

Where, $D$ is gas drainage pipe diameter, $\mathrm{m} ; Q$ is gas flow in the gas pipe, $\mathrm{m}^{3} / \mathrm{min} ; V$ is average gas velocity in the gas pipe, $\mathrm{m} / \mathrm{s}$.

According to the maximum value of various pipeline flows and the service life, taking the richness factor of 1.2 1.8; here it is 1.2 ; the average gas velocity in the gas pipe is generally $5 \sim 10 \mathrm{~m} / \mathrm{s}$, which is $10 \mathrm{~m} / \mathrm{s}$. Substituting into equation (1), the calculated diameter of the gas extraction pipe is $521.36 \mathrm{~mm}$. According to the principle of selection, the inner diameter of $580 \mathrm{~mm}$ should be selected. When the extraction concentration is calculated at $20 \%$, the maximum extraction gas purity of the low negative pressure gas drainage system is $21.34 \mathrm{~m}^{3} / \mathrm{min}$ when the annual production reaches 1.50 million tons per year.

Pipe friction resistance calculation formula (2) [13]:

$$
h_{f}=\frac{9.8 L \gamma Q^{2}}{k d^{5}}
$$

Where, $h_{f}$ is resistance loss, $\mathrm{Pa}$; $L$ is pipe length, $\mathrm{m} ; Q$ is gas flow, $\mathrm{m}^{3} / \mathrm{h} ; \gamma$ is the relative density of mixed gas to air, $\gamma=0.911 ; k$ is the coefficient associated with the pipe diameter; $d$ is pipe inner diameter, $\mathrm{m}, d=58 \mathrm{~cm}$.

Referring to the actual situation of the Tashan Mine to draw the maximum distance of $8000 \mathrm{~m}$; take the gas flow: $(21.34 / 20 \% * 60=6402) \mathrm{m}^{3} / \mathrm{h}$; since the diameter is more than $150 \mathrm{~mm}$, set $\mathrm{k}=0.71$; the resistance loss of the pipeline is $6288 \mathrm{~Pa}$. The local resistance of the pipeline is calculated according to the frictional resistance of $10 \% \sim 20 \%$. 
Combined with the actual situation of Tashan Mine, it is calculated as $15 \%$ of the low negative pressure pipeline. The local resistance loss of the pipe was found to be $944 \mathrm{~Pa}$.

The gas pump pressure is calculated according to formula (3) $[14]$ :

$$
H=K\left(h_{k}+h_{r m}+h_{r j}+H_{c}\right)
$$

Where, $H$ is gas pumping pump pressure required, $\mathrm{Pa} ; K$ is pressure reserve factor, $K=1.2 ; h_{k}$ is drilling hole negative pressure, $\mathrm{Pa}, h_{k}=7000 \mathrm{~Pa} ; h_{r m}$ is the maximum frictional resistance of the underground pipe network, $h_{r m}=6288 \mathrm{~Pa} ; h_{r j}$ is the maximum local resistance of the underground pipe network, $\mathrm{Pa}, h_{r j}=944 \mathrm{~Pa} ; H_{c}$ is gas pump outlet positive pressure, $\mathrm{Pa}, H c=5000 \mathrm{~Pa}$.

The pumping pressure of the gas pump required for the calculation of the low negative pressure gas drainage system is $40435 \mathrm{~Pa}$. Absolute pressure at the pump inlet: (90307-40435=49872)Pa. (The atmospheric pressure at the extraction station is $90307 \mathrm{~Pa}$ ), The absolute pressure at the actual pump inlet is $50000 \mathrm{~Pa}$.

Gas pump flow calculation formula (4) [14]:

$$
Q_{b}=\frac{Q \cdot K}{X \cdot \eta}
$$

Where, $Q_{b}$ is gas pump rated flow, $\mathrm{m}^{3} / \mathrm{min} ; Q$ is the maximum amount of gas discharged from the mine, $\mathrm{m}^{3} / \mathrm{min}$, $Q=21.34 \mathrm{~m}^{3} / \mathrm{min} ; K$ is comprehensive coefficient of gas drainage, $K=1.2 ; X$ is gas concentration at the inlet of the gas pump, $20 \% ; \eta$ is gas pump mechanical efficiency, $\boldsymbol{\eta}=0.8$.

As a result, under standard conditions, the rated flow of the low negative pressure gas pump is: $Q_{\text {low }}=160.05 \mathrm{~m}^{3} / \mathrm{min}$.

At the same time, since the flow rate of the vacuum pump is drawn under standard conditions, it is also necessary to convert the gas flow in the standard state into the flow rate under the working condition to select the gas extraction pump.

Gas pump flow calculation formula (5):

$$
Q_{g}=Q_{s} \times P_{s} \times T_{1} /\left(P_{1} \times T_{s}\right)
$$

Where, $Q_{S}$ is gas flow under standard conditions, $Q_{S}=160.05 \mathrm{~m}^{3} / \mathrm{min} ; P_{S}$ is standard atmospheric pressure, $P_{S}=101325 \mathrm{~Pa} ; T_{1}$ is gas pump inlet gas absolute temperature, $T_{1}=280 \mathrm{~K} ; P_{1}$ is gas pump inlet absolute pressure, $P_{1}=5000 \mathrm{~Pa}$; $T_{S}$ is absolute temperature in the standard state specified by the gas drainage standard, $\left(T_{S}=273+t\right) \mathrm{K}, \mathrm{t}$ is the temperature of the gas inlet of the gas pump, $t=20^{\circ} \mathrm{C}$; $Q_{g}$ is gas pump flow under working conditions, $\mathrm{m}^{3} / \mathrm{min}$.

As a result, $Q_{g}=309.95 \mathrm{~m}^{3} / \mathrm{min}$.

The gas drainage pipeline should be set according to the location of the underground drainage, the distribution of the roadway, the development plan of the mine and the convenience of installation and maintenance. The underground gas drainage pipeline is laid along the roadway floor by hanging and supporting. The excavation face is laid on the side of the roadway by means of hanging. The ground is laid along the surface of the ground to lay the gas drainage pipeline, the overhead height is $1.5 \sim 2.5 \mathrm{~m}$, the support pier is set every $5 \sim 6 \mathrm{~m}$, and the drainage pipeline is fixed on the support pier.

\section{Application of Gas Control Measures in Tashan Coal Mine}

In addition to the measures of gas extraction to prevent gas explosion in Tashan Coal Mine, we should also monitor the gas concentration in real time during the coal mining process to effectively ventilate and control the fire source, and prevent gas explosion.

\subsection{Gas Concentration Real-time Monitoring}

Real-time monitoring and early warning of gas concentrations in mines is also an effective means of preventing gas explosions. Combined with the actual situation of Tashan Mine, the WIFI network system is used to conduct real-time uninterrupted monitoring of underground gas. The ground control room is connected to the underground base station via the auxiliary shaft through the optical fiber, and the wireless access point is installed at the corner of the straight roadway and the ramp every $200 \mathrm{~m}$ to ensure the stability of the transmission, and then the data monitored by the wireless sensor is transmitted to the ground. The control room monitors the condition of the underground gas in real time and alarms when it exceeds the limit.

The setting of the gas sensor in the coal mining face [15]. The gas sensor at the corner of the return air at the coal mining face is installed under the bracket at the head of the working face. The gas sensor of the working face is hung at a position $10 \sim 15 \mathrm{~m}$ away from the coal wall of the working face. The gas sensor in the return airway is suspended between $10 \sim 15 \mathrm{~m}$ in the mixed return air point. The gas sensor in the heading face is hung on the other side of the air duct, less than $5 \mathrm{~m}$ from the head, as shown in Figure 4.

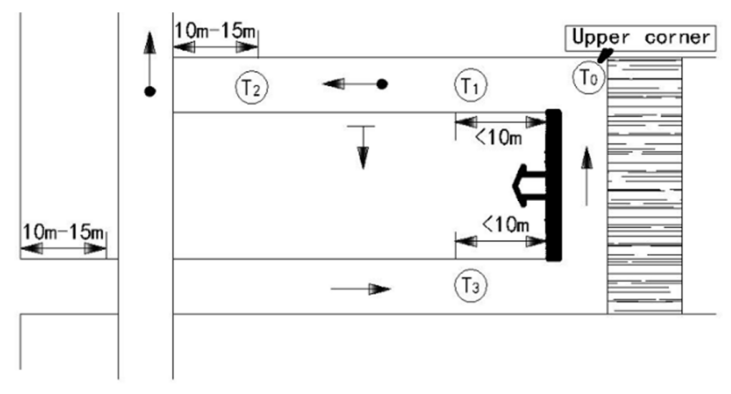

Figure 4. Gas sensor setting of mine coal face.

$\mathrm{T}_{0}$-upper corner setting methane sensor; $\mathrm{T}_{1}$-face setting high and low concentration gas sensor; $\mathrm{T}_{2}$-high and low concentration gas sensors are arranged in the return air passage of the working face; $\mathrm{T}_{3}$-high and low concentration gas sensor on the inlet side of the working face

The gas sensor setting of the heading face [15]. The gas sensor of the heading face is placed near the working face and where the wind flow is stable, as shown in Figure 5. 


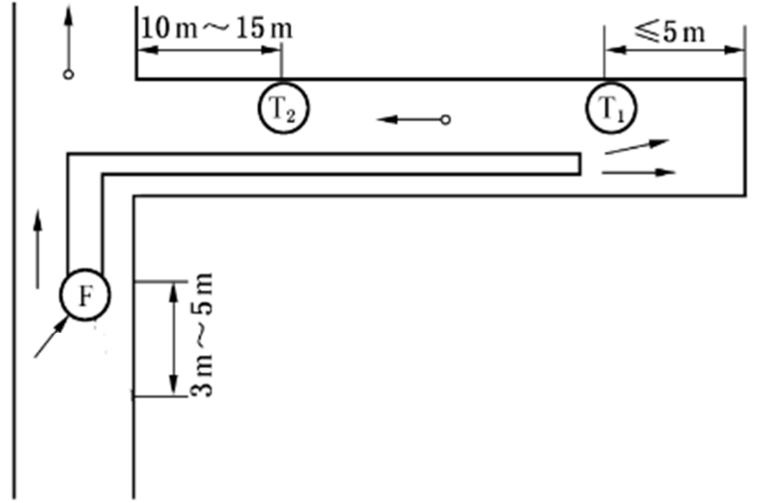

Figure 5. Gas sensor settings for the heading face.

$\mathrm{T}_{1}$-working face setting high and low concentration gas sensor; $\mathrm{T}_{2}$-high and low concentration gas sensor in return air flow

Gas sensor settings for electronic chambers [15]. In the return air flow, the gas concentration of the electronic chamber may be relatively high, and a gas sensor should be installed on the inlet side of the electronic chamber in the return air flow, as shown in Figure 6.

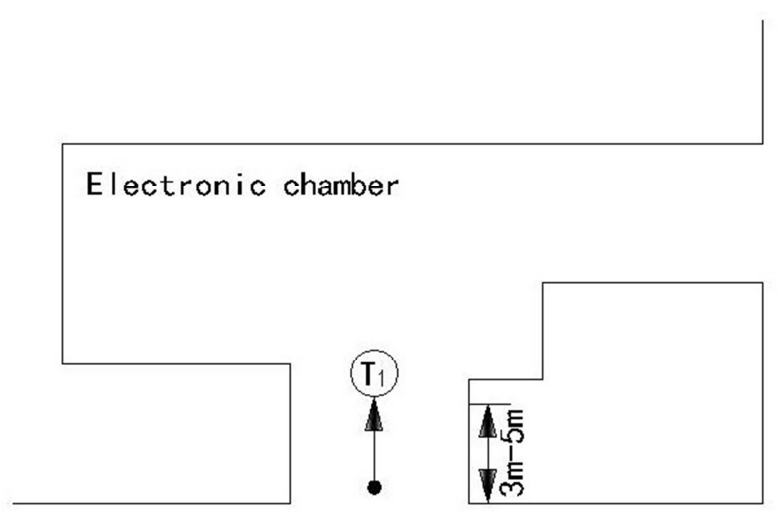

Figure 6. Gas sensor settings for electronic chamber.

$\mathrm{T}_{1}$-Gas sensor is set at the air inlet side of the mechanical and electronic chamber

In addition, the gas sensor is set in the air flow of the loading point, the air flow of the transportation lane, and the indoor input pipeline of the gas drainage pump station. At the same time, the gas monitor should use the gas monitor from time to time to monitor the places prone to gas accidents and high gas concentration to avoid gas concentration exceeding the limit.

\subsection{Effective Ventilation}

Effective ventilation is the most effective and basic method to prevent gas accumulation. At the moment, the coal mine should be stable at all times to avoid the occurrence of circulating wind. The local ventilator should be as close as possible to the excavation and coal mining face, and the ventilation should not be interrupted during the explosion, and the ventilation and wind speed should be increased where the gas accumulates. In addition to the use of ventilation to prevent the accumulation of gas, it is also necessary to deal with the local accumulation of gas in a timely manner.

The pulsating fan is installed near the corner of the coal working face to disturb the wind flow at the upper corner to prevent the accumulation of gas at the coal working face. For the gas accumulation in the fully mechanized mining face, due to its high output and fast speed, on the one hand, it is necessary to increase the air volume of the working face; on the other hand, a small local ventilator or a wind and water ejector can be installed to increase the vicinity of the shearer wind speed to prevent gas accumulation. For the accumulation of gas near the top plate, an air deflector may be placed under the top beam to direct the wind flow to the vicinity of the top plate or a compressed air pipe with a short pipe to blow the accumulated gas. For the gas accumulated in the caving cavity of the roof, it can be filled with sand, or the wind deflector and the air duct can be used to blow the airflow.

\subsection{Elimination and Control of Fire Sources}

As one of the factors of gas explosion, fire source should prevent the generation of sparks such as blasting, electrical, static and frictional impact in the underground production process [16]. First, it is necessary to strengthen the management of underground electrical equipment, using explosion-proof electrical equipment, even if the underground electrical equipment is out of explosion, it can also isolate the electric spark and arc in the shell, and avoid the fire source from appearing outside the shell to cause gas explosion. After each shift, it should be inspected and repaired, and the electrical equipment that cannot be repaired should be replaced in time. The staff who operate electrical equipment should be regularly educated and trained to avoid misuse. The second is to prevent the gas from being detonated during the shooting process. The coal dust in the Tashan Mine has an explosion hazard. In the process of mining, safe explosives and instant detonators are used. In the process of shooting, strict implementation of the "one shot three inspections" rules and regulations to avoid causing gas explosions; it is also possible to spray water mist a few minutes before blasting and during blasting. The third is to install a power supply locking device. Wind power locking devices must be installed on electrical equipment and local fans in the tunneling face. The gas electrical lockout device is installed in the return air passage of the fully mechanized mining face and the electronic chamber in the return air flow. In addition, it is necessary to prevent the friction of the down hole machinery and equipment to generate sparks. For the poorly conductive transport tape and the pipe for gas drainage, anti-static and flame retardant polymeric materials should be used.

\section{Conclusion}

The Tashan Mine was a high-gas mine. Once gas explosion in the underground occurred, it would cause extremely serious damage. It would not only destroy the roadway and equipment, but also cause a large number of casualties. Therefore, it was particularly important for coal 
mine to prevent gas explosion effectively.

1) In this paper the No.3 5 coal seam of Datong Tashan Mine in Shanxi were taken as an example. Based on the analysis of its hydrogeological conditions, developing methods and coal mining methods, and according to its gas content and coal seam gas drainage method, the gas drainage pump with a flow rate of $309.95 \mathrm{~m}^{3} / \mathrm{min}$ was designed. The underground gas drainage pipeline was laid along the roadway floor by hanging and supporting. The tunneling face was laid on the side of the roadway by means of hanging. The ground was laid along the surface of the road to lay the gas drainage pipeline.

2) Integrated control technologies like gas drainage, gas concentration monitoring, effective ventilation and control of fire sources in the No.3 5 coal seam of Tashan Mine was applied to reduce its gas explosion probability, so as to ensure the safety operation of coal mine.

\section{Acknowledgements}

Financial support for this work, provided by Shaanxi Province Science and Technology Plan Funds (Program №2013K11-20), Scientific Research Program Funded by Shaanxi Provincial Education Department (Program №2013JK0868), China Post-doctor Science Fund (Program №2013M542366), and Doctor Startup Fund Program Funded by Xi'an University of Science and Technology (Program №2013QDJ027) are gratefully acknowledged.

\section{References}

[1] Wang Cheng, Zhao Yongyao, EK Addai, Investigation on propagation mechanism of large scale mine gas explosions, Journal of Loss Prevention in the Process Industries, 2017, 49: 342-347.

[2] Nian Qifeng, Shi Shiliang, Li Runqiu, Research and application of safety assessment method of gas explosion accident in coal mine based on GRA-ANP-FCE, Procedia Engineering, 2012, 45 (02): 106-111.

[3] L Muduli, DP Mishra, PK Jana, Application of wireless sensor network for environmental monitoring in underground coal mines: A systematic review, Journal of Network and Computer Applications, 2017.

[4] Song Xiaoyan, Xie Zhongpeng, Application of man-machine-environment system engineering in coal mines safety management, Procedia Engineering, 2014, 84 (02): 87-92.

[5] Yang Chunli, Li Xiangchun, Ren Yanbin, Statistical analysis and countermeasures of gas explosion accident in coal mines, Procedia Engineering, 2014, 84 (84): 166-171.

[6] Xu Xin, Research on prediction and early warning model of gas explosion disaster in coal mine Internet of Things[D], Hebei University of Engineering, 2017.

[7] Gao Mu, Analysis of coal mine gas monitoring system based on wirelesssSensor network [J], China New Technology and New Products, 2017 (23).

[8] Xie Guomin, Shan Minzhu, Fu Hua, Risk pattern recognition of coal mine gas explosion based on FOA-SVM [J], Control Engineering, 2018 (10).

[9] Chu Tingxiang, Yu Minggao, Jiang Deyi, et al. Theoretical study on gas drainage in goaf of "U+I" type coal face [J], Journal of China University of Mining \& Technology, 2015, 44 (06): 1008-1016.

[10] Zhang Yiqing, Analysis of gas drainage equipment in coal mines[J], Energy \& Energy Conservation, 2019 (6): 187-188.

[11] Li Guoxiong, Sun Dening, Wang Hongcun, et al. Design of gas drainage piping system and matching selection of equipment [J], Industrial Automation, 2012, 38 (02): 78-81.

[12] China Coal Construction Association, Design standard for coal mine gas drainage engineering: GB 50471-2018 [S], Beijing: China Planning Press, 2018.

[13] Cui Guohong, Calculation and application of pipe frictional resistance calculation in coal mine gas drainage system $[\mathrm{J}]$, Journal of Shanxi Coal Management Cadre College, 2018 (6).

[14] Zhang Yi, Selection and design of coal mine gas drainage equipment [J], Coal Mine Machinery, 2018.

[15] Liang Huiqi, Research and application of gas sensor layout in coal mine monitoring and control system [J], Mechanical Management and Development, 2019, 34 (03): 158-160.

[16] Coal mine safety regulations [M], Coal Industry Press, State Administration of Work Safety, 2016. 